\title{
A Comparative Study To Evaluate The Fracture Resistance of Posterior Teeth Restored With Ceramic Inlay And Hybrid Composite Restoration - An In-Vitro Study.
}

\author{
Dr. M Kala ${ }^{1}$, Dr. Mayank Shailat ${ }^{2}$ \\ ${ }^{I}$ Professor and head of department (Department of Conservative Dentistry and Endodontics, Government \\ Dental college and Research Institute/ Rajiv Gandhi University of Health Sciences, India) \\ ${ }^{2}$ Post graduate student (Department of Conservative Dentistry and Endodontics, Government Dental college \\ and Research Institute/ Rajiv Gandhi University of Health Sciences, India)
}

\begin{abstract}
:
Background \& Objectives: The objective of this in-vitro study was to compare and evaluate the fracture resistance of posterior teeth restored with Ceramic inlay and Hybrid composite restoration.

Methods: Thirty intact, non-carious, human maxillary premolar teeth that were collected. The thirty teeth were randomly divided into 3 experimental group of 10 teeth each, Group A, Group B and Group C. Group A was consisted of sound/unprepared teeth (control). In Group B mesio-occlusal Class-II cavity was prepared in each tooth and restored with Hybrid composite resin. In Group C mesio-occlusal Class-II inlay cavities were prepared and restored with Ceramic inlays. Thereafter, the specimens all three groups were individually tested in a universal testing machine. All specimens were loaded by compression force until the specimens fractured. The ultimate fracture load was recorded. Data collected by experiments were computerized and analysed using Statistical Package for Social Sciences (SPSS) version 17.0. Statistical analysis was done using Unpaired student's t test.

Results: The results showed that Group C had highest kilo newton $(K N)$ values for fracture resistance compared to Group B . Null hypothesis was rejected as fracture resistance of Group $C$ was significantly higher than Group B. However, Group A and Group B did not differ significantly in fracture resistance from eachother. Between Group C and Group A the average kilonewton (KN) value for fracture resistance for Group $C$ was significantly higher than Group A. Conclusion: From this in-vitro study it can be concluded that adhesively bonded restorations such as composite and ceramic inlays are good and optimal replacement for lost tooth structure.Ceramic inlay is better restorative alternative as compared to direct composite resin as far as the fracture resistance is concerned.
\end{abstract}

Keywords: Fracture resistance, Hybrid composite resin, Ceramic inlay, Universal testing machine.

\section{Introduction}

During restorative treatment of posterior teeth, removal of tooth structure through cavity preparation has been shown to weaken teeth and increase their susceptibility to fracture. ${ }^{1}$ Studies on the weakening of teeth by class I and class II cavity preparations and the effect of restorations in strengthening of the prepared tooth have been conducted experimentally. ${ }^{2}$ Depending on the extent of the class I and class II cavity, restorative treatment is planned and most appropriate restorative material is used to restore the prepared tooth cavity. Today there are numerous Dental materials from which the material can be selected for restoring cavities prepared on posterior teeth. These Dental materials include Silver amalgam, Composite, Glass ionomer cement, Gold inlays, Cast metals, Ceramics.

Silver amalgam has successfully served the profession for over a century. Silver amalgam is appropriate for use in individuals of all ages, in stress-bearing situations for restoration of small-to moderatesized cavities on posterior teeth. Silver amalgam is used in posterior teeth for its high compressive strength and longevity. ${ }^{3}$ The main reasons for restoration failure are secondary caries, fracture of restoration with insufficient bulk or fracture of the remaining tooth structure, loss of mechanical retention, marginal deficiencies and wear. ${ }^{4}$ The major drawbacks of Silver amalgam restorations are brittleness, low tensile strength, dark appearance and mercury toxicity. ${ }^{3}$

Gold is used as restorative material in conservative dentistry, either as a pure metal, or alloyed together with noble metals and base metals. The use of pure gold is limited to direct filling of small occlusal cavities. In recent years pure gold has also been used through the electroforming process. Electroformed inlays and onlays are suitable to be cemented into prepared cavities after they have been veneered with porcelain. Inlays, onlays and partial crowns from high gold alloys can be precisely fabricated in the dental laboratory with an excellent 
marginal fit and longevity for many years. ${ }^{5}$ Causes of gold inlay failures are recurrent caries, periodontal breakdown, sensitive teeth, tooth fracture, poor esthetics, and loss of retention. ${ }^{6}$

Glass ionomer cement is a good asthetic material which bonds chemically as well as mechanically to the tooth structure, it is used to restore small to moderate size tooth cavity. One of the advantages of glass ionomer cement, compared to other restorative materials, is that they can be placed in cavities without any need for bonding agents7 ,they also have good biocompatibility. ${ }^{7,8}$ Posterior Composite resins offer excellent esthetic potential and acceptable longevity without the need for extensive sound structure preparation, allowing minimally invasive preparation or sometimes no preparation at all.

Posterior composite resins with improved mechanical properties are used for restoration of small to moderate size cavities on posterior teeth. Some of the disadvantages of posterior composites resins are polymerization shrinkage, microleakage, post operative sensitivity and discolouration over a period of time. Manufacturers are working aggressively to improve resin composite materials by modifying components to decrease polymerization shrinkage, to improve mechanical and physical properties, and to enhance handling characteristics. The main causes of failure of posterior composite restoration are microleakage which leads secondary caries and fracture of either restoration or tooth. ${ }^{9}$

Time-saving restorative materials are an ongoing demand for posterior applications. A new resinbased composite (RBC) material class, the bulk-fill resin based composites, has been introduced in the past few years. They are mainly used for class I and class II restorations. They are an attempt to speed up the restoration process by enabling up to $4 \mathrm{~mm}$ or $5 \mathrm{~mm}$ thick increments to be cured in one step, thus skipping the time-consuming layering process. Bulk-fill resin based composites are also marketed as restoratives that are particularly well suited for patients with limited compliance. Moreover, the rheology of these materials is thought to have changed, thus allowing a better adaption to the cavity walls and resulting in a self leveling effect. ${ }^{10}$

Ceramic is said to be the most biocompatible material in dentistry. Ceramic has been well used in dentistry since many years. The disadvantages of ceramics are porcelain weakness, microleakage, cement failure, and poor fit. Recent developments in dental material science have led to the development of all ceramic material with high strength. It is chemically indestructible in oral environment. Its colour translucency and vitality cannot be matched by other materials.

This is due to qualities like esthetic, long-lasting material, and to the ability to effectively bond metalfree ceramic restorations to tooth structure using acid-etch techniques and adhesive cements, which attributed to its usage. Ceramics possess distinct advantages when compared with resin composites. Generally ceramics exhibit incomparable esthetics, superior wear resistance, and exceptional bond strength to tooth structure when bonded adhesively. Indirect aesthetic adhesive restorations have been clinically accepted restorations for posterior teeth.

Ceramic inlays are indicated where esthetics and structural reinforcement become primary requisites and tooth preparation goes beyond the recommended limits for direct application of resin composites. This is particularly true in cases involving complex restorations or mesio-occlusodistal preparations in which the isthmus width covers half or more of the distance between cusp tips. ${ }^{11,12}$ Indirect inlays are adhesively bonded to teeth using resin cements which have a higher bond strength to tooth compared to other luting agents, such as zinc phosphate and glass-ionomer cements. ${ }^{1,14}$ Strong, complete bonding of the inlay to tissue potentially results in an increase in tooth fracture resistance. ${ }^{15}$

According to some authors, ceramic inlays maintain better anatomic form of the surface and exhibit better marginal integrity, ${ }_{16,17}$ as well as stabilize the weakened cusps better than composite resin inlays. ${ }^{18,19}$ Others report improved marginal adaptation ${ }^{20}$ and higher strength of teeth restored with composite resin inlays compared to ceramic inlays. ${ }^{21-23}$ Still other reports have shown that the fracture resistance of teeth with both ceramic and composite resin inlays is similar. ${ }^{24-27}$ Previous studies on strength of teeth restored with ceramic or composite resin inlays could not resolve which restoration material provides greater strength and marginal integrity. ${ }^{28,29}$ The aim of this In vitro study was to compare and evaluate the fracture resistance of posteior teeth restored with high strength Ceramic inlay and Hybrid composite restoration.

\section{MATERIAL AND METHOD}

Thirty intact, non-carious, human maxillary premolar teeth that were planned for orthodontic extraction within six month period of start of the study were used in this study. Extracted teeth were handled as per the recommendation and the guidelines laid down by Occupational Safety and Health Administration (OSHA) and Center for Disease Control (CDC). Teeth were free of caries, cracks and restorations, teeth were thoroughly rinsed in running water. Any calculi and soft tissue deposits were removed with hand scaler (Gracey Hu-Friedy scaler). The teeth were cleaned properly with prophylactic paste using rubber cup and were then stored in a beaker in $0.9 \%$ normal saline solution at room temperature.

The thirty teeth were randomly divided into 3 experimental group of 10 teeth each :

Group A - comprising sound/unprepared teeth (control). 
Group B-comprising of Class-II direct composite resin restored teeth.

Group C - comprising Class-II ceramic inlay restored teeth.

Teeth in the three different groups were treated as follows:

Group A: Consisted of Sound/unprepared teeth which were kept intact as control for comparison with study groups.

Group B: Class-II mesio-occlusal cavity was prepared in each tooth using a tungsten carbide straight fissure bur (FG 172, KERR Haw, Canada) using high-speed water-cooled hand piece (NSK, Japan) with

$2 \mathrm{~mm}$ depth pulpally, $4 \mathrm{~mm}$ deep in proximal boxes, width of cavity was $1 / 3 \mathrm{rd}$ of intercuspal distance, and cavosurface angle was beveled using flame shaped diamond finishing bur (NeoDiamond, Finishing Burs - FG, Canada). Standardized depth was verified with a scaled periodontal probe (Instrument number 23/ UNC 15; Hu Friedy, Chicago, IL, USA). Prepared cavities were thoroughly rinsed with water and excess moisture was removed with faint air jet leaving dentinal surface slightly moist. For restoration of prepared cavities with Hybrid bulk fill composite resin (X-tra fil, bulkfill, Voco, Germany) etching and bonding of prepared cavities was done with bonding agent (Bondfix, Self etch bond, Voco, Germany). A moderately thin layer of bonding agent was applied on enamel and dentine using an applicator and was allowed to act for 20 seconds, bonding agent layer was dried with air jet for atleast 5 seconds. Polymerisation of bonding agent was done with blue LED light (DP387 LED curing light, Foshan, China) for 10 seconds. The Toffelmire retainer system was applied with ultra thin metal band and teeth were restored with Hybrid composite resin (X-tra fil, bulkfill, Voco, Germany) followed by light curing with blue LED curing light (DP387 LED curing light, Foshan, China) was done for 10 seconds according to the instructions given by the manufacturer.

Group C: Class-II mesio-occlusal inlay cavity was prepared using inlay cavity cutting Carbide burs no.271and $169 \mathrm{~L}$ to prepare inlay cavity with $2 \mathrm{~mm}$ depth pulpally, $4 \mathrm{~mm}$ deep in proximal boxes, width of cavity was $1 / 3$ rd of intercuspal distance, and cavo surface angle was not beveled. Custom impression tray was built using self cure acrylic resin. Impression of prepared tooth was taken with an addition silicon impression material in an individual plastic custom tray and working cast was prepared in investment material in vacuum mixer. wax pattern of inlay was prepared on the working cast. Inlay wax pattern was invested in gypsum investing material using ring former, investment mold was formed and wax burnout was carried out at 830 degree Celsius in the furnace, after wax burnout IPS e.max Lithium Disilicate (Ivoclare Vivadent, India) ceramic ingot was placed in investment mold and the mold was kept in the pressing machine (Multimatch 2 plus press machine) for fabrication of ceramic inlay restoration. Ceramic inlay restorations were finished and the internal fits of restorations were evaluated. Restorations were measured with thickness gauge and an occlusal thickness of 1.5$2 \mathrm{~mm}$ was considered as adequate. Internal or adhesive surface of ceramic inlay was treated with $10 \%$ hydrofluoric acid (Porcelain etchant, Angelus, Brazil) solution for 20 seconds, and then rinsed with water and then air dried. These etched porcelain surfaces were treated with a silane coupling agent (Ultradent ) for 1 minute. Enamel surfaces of cavities were air dried and then treated with bonding agent (Bondfix, Self etch bond, Voco, Germany). A moderately thin layer of bonding agent was applied on enamel and dentine using an applicator and was allowed to act for 20 seconds, bonding agent layer was dried with air jet for atleast 5 seconds. Polymerisation of bonding agent was done with blue LED light for 10 seconds. Ceramic inlays were cemented with dual cure ( Paracore,Coletene, Switzerland) adhesive cement. Cement was hand mixed and applied to both prepared teeth and ceramic inlay restoration. After seating of restoration on the prepared teeth once cement sets, excess cement was removed with scaler followed by light curing and polymerisation of dual cure cement using blue LED curing light (DP387 LED curing light, Foshan, China), light curing was done for 10 seconds according to the instructions given by the manufacturer. Finishing burs were used to futher remove excess cement and smoothen the surface of teeth.

Each tooth was vertically positioned in the center of the plastic ring mould. Its root was embedded in a plastic cylinder of self-curing acrylic resin (Dentsply Ltd. UK). Each cylinder was $20 \mathrm{~mm}$ in height and $15 \mathrm{~mm}$ in diameter, each tooth was embedded up to $1.0 \mathrm{~mm}$ below the cementoenamel junction. Each tooth was carefully positioned to maintain the occlusal surface parallel to the cylinder's base to permit correct alignment and prevent oblique forces during the axial compression test. Before the fracture strength test, the specimens were stored in distilled water at room temperature for 1 week. Thereafter, the specimens were individually tested in a universal testing machine (Model- KUT 20, Ratnakar Enterprises, Maharashtra, India) at a crosshead speed of $0.5 \mathrm{~mm} / \mathrm{min}$. For this purpose, a $3 \mathrm{~mm}$ diameter cylindrical bar was mounted in the moving arm, which was in contact with the occlusal surface of the tooth during the fracture test. All specimens were loaded by compression force until fracture. The ultimate fracture load was recorded. 


\section{Observation And Results}

Data collected by experiments were computerized and analysed using Statistical Package for Social Sciences (SPSS) version 17.0. Results were expressed as the mean and standard deviation between the three main groups Group A Intact unprepared teeth, Group B comprising of Class-II direct composite resin (X-tra fil, bulkfill, Voco, Germany). restored teeth. Group C comprising Class-II ceramic inlay- IPS e.max Lithium Disilicate Ceramic (Ivoclare Vivadent, India) restored teeth. The three main groups were compared with respect to final fracture resistances of the specimens using Student's $t$ test. A probability value of $<0.05$ was considered to be statistically significant.

Out of the three groups Group $\mathrm{C}$ had the highest kilo newton $(\mathrm{KN})$ values for fracture resistance of teeth followed by Group A. Whereas Group B had the lowest kilo newton $(\mathrm{KN})$ values for fracture resistance of teeth. Statistical analysis was done using Unpaired student's $t$ test. We found that Group C had highest kilo newton $(\mathrm{KN})$ values for fracture resistance compared to Group B ( $\mathrm{t}=0.67$, d.f. $=18, \mathrm{P}<0.05$ ). Null hypothesis was rejected as fracture resistance of Group C was significantly higher than Group B . However, Group A and Group B did not differ significantly in fracture resistance from eachother $(t=0.12$, d.f $=18, \mathrm{P}>0.05)$. Between Group $\mathrm{C}$ and Group A the average kilonewton $(\mathrm{KN})$ value for fracture resistancefor Group $\mathrm{C}$ was significantly higher than Group A $(\mathrm{t}=0.58$, d.f $=18, \mathrm{P}<0.05)$.

IV. Figures and Tables

Table 1: Fracture resistance of three groups measured in Kilo Newton (KN)

\begin{tabular}{|c|c|c|c|}
\hline S.No. & Group A & Group B & Group C \\
\hline 1. & $1.24 \mathrm{KN}$ & $1.04 \mathrm{KN}$ & $0.84 \mathrm{KN}$ \\
\hline 2. & $1.04 \mathrm{KN}$ & $1 \mathrm{KN}$ & $1.12 \mathrm{KN}$ \\
\hline 3. & $1.16 \mathrm{KN}$ & $1.4 \mathrm{KN}$ & $1 \mathrm{KN}$ \\
\hline 4. & $1.16 \mathrm{KN}$ & $1.16 \mathrm{KN}$ & $1.2 \mathrm{KN}$ \\
\hline 5. & $1.2 \mathrm{KN}$ & $1.2 \mathrm{KN}$ & $1.16 \mathrm{KN}$ \\
\hline 6. & $1.4 \mathrm{KN}$ & $1.4 \mathrm{KN}$ & $1.6 \mathrm{KN}$ \\
\hline 7. & $1.52 \mathrm{KN}$ & $1.52 \mathrm{KN}$ & $1.76 \mathrm{KN}$ \\
\hline 8. & $1.5 \mathrm{KN}$ & $1.48 \mathrm{KN}$ & $1.96 \mathrm{KN}$ \\
\hline 9. & $1.8 \mathrm{KN}$ & $1.8 \mathrm{KN}$ & $1.88 \mathrm{KN}$ \\
\hline 10. & $1.72 \mathrm{KN}$ & $1.6 \mathrm{KN}$ & $2.2 \mathrm{KN}$ \\
\hline
\end{tabular}

$\mathrm{KN}$ - Kilo Newton - require to the fracture tooth

\section{Discussion}

The world wide prevalance of Dental caries is 90 percent among adults. Posterior teeth cavities are restored with various Dental restorative materials, which are Silver amalgam, Gold inlays, Type II Glass ionomer cement, Posterior composite resins and Ceramics. ${ }^{31}$ When substantial tooth structure is lost due to dental caries on posterior tooth surfaces, in such conditions tooth is restored with inlays and onlays. Inlays are known to strengthen the tooth structure. After an inlay restoration a tooth can bear upto 50 to 75 percent more chewing forces. An inlay is indicated for restoration of tooth with extesive dental decay, correction of occlusion, when superior contacts and contours are desired, restoration of subgingival lesions, and when superior esthetics and finish are required. Inlays are contraindicated in developing and deciduous teeth, patients with high plaque index, bruxism, extensive occlusal wear facets involving remaining ridge of the tooth. Inlays can be made of gold, metal alloy, ceramic or composite materials.

Composite resins restorations are widely used for restoration of posterior teeth. Composites are used either as direct or indirect adhesive restorations. Composite resins are Both direct and indirect composite restorations exhibit similar flexure strength, flexure modulus, and hardness. ${ }^{32}$ Direct composite restorations have been considered as one of the most favorable restorations, mainly due to their high compressive strength,tensile strength, excellent esthetics, easier to polish, preservation of more sound tooth structure, cost is less, less abrasive to opposing tooth, less time consuming and the fact that the restoration is placed in a single visit. ${ }^{33,34}$ Indirect composite and ceramic restorations are among other commonly practiced posterior restoration techniques but their use is more time-consuming. ${ }^{35}$

However, primary reason for failure of Composite resin restoration was postoperative sensitivity, shrinkage of few percent in volume during hardening which leads to polymerization shrinkage and stress, microleakage, marginal discolouration of restoration, fracture of tooth or restoration, wear off, loss of bond between tooth, and restoration or loss of marginal adaptation and secondary caries. ${ }^{32}$

Composite material used in present study was a Hybrid composite resin. Hybrid composite resin has average filler particle size ranging between 0.6 to 1 micron, this distribution of particle size maximizes filler 
loading, filler loading is upto 70 to 80 percent by weight, which improves strength, handling property, aesthtics, polishability and reduced stickiness.

All-ceramic inlay restorations are superior in terms of compressive strength, esthetics, biocompatibility, colour stability, and wear resistance. ${ }^{36,37,38}$ There is limited marginal deterioration; therefore, they are not predisposed to marginal discoloration or secondary caries. Patients rarely suffer from postoperative sensitivity after placement of the ceramic inlay. ${ }^{39}$ Several studies have also shown that the all-ceramic inlay restorative procedure can provide a tooth strengthening effect. ${ }^{25}$ However, they have some disadvantages, such as fragility, the need for a specialized laboratory, high cost and wear on the antagonistic tooth.

In the last few years, many types of all-ceramic materials, with high values of compressive strength, have been developed and improved adhesive techniques have enabled their use in many clinical situations. ${ }^{31}$ With the development of dentin adhesive systems with high bond strength and the introduction of resin luting cements, the all-ceramic inlay became another restorative option for posterior teeth. Resin cement used for cementation of adhesive restoration is elastic and tends to deform under stress making them capable of absorbing more stress. Therefore, success of ceramic inlay is also dependent on the creation of an uncompromised adhesive tooth ceramic interface. ${ }^{39}$ Heat pressed All ceramic materials are either leucite (KAlSi2O6 or K2O.A12O3.4SiO2) based or Lithium Disilicate (Li2Si2O5) based as a major crystal. The mechanical property of ceramic materials are maximized in heat pressed system due excellent crystal dispersion, higher crystallinity, and smaller crystal size.

The ceramic material used in present study was a Second generation pressible ceramic, IPS e.max Lithium Disilicate. Lithium disilicate (LS2) glass-ceramic is ideally suitable for the fabrication of monolithic single-tooth restorations. This innovative ceramic provides highly esthetic results and, compared to other glassceramics, demonstrates a strength that is 2.5 to 3 times higher than other ceramics, given the high strength of 360-400 MPa, the restorations offer flexible cementation options.

Teeth becomes more brittle with age and are therefore more susceptible for cracking and fracture especially if the tooth has been weakened by restorative procedure. ${ }^{40}$ The effect of masticatory stresses on teeth either restored or unrestored is variable. Sound teeth rarely fracture from masticatory stresses, but cusp fracture may occur in teeth with cavity preparation and restorations. ${ }^{41}$ Cavity preparations significantly weaken the remaining tooth structure. Direct and indirect intracoronal adhesive restorations can partly restore fracture resistance of teeth weakened by wide cavity preparation. ${ }^{42}$ Therefore, adhesive restorations are useful to reinforce the tooth weaken by cavity preparation. ${ }^{43}$ The findings of the present study are consistent with those of previous investigations $45,46,47$, which consider that acid etching and adhesive techniques do reinforce dental structure in a way that the stiffness values of restored teeth approximate the values of sound teeth. Ceramic inlays with $1 / 2$ or $1 / 3$ of the intercuspal distance, luted with resin cements, can recover tooth strength near that of intact teeth. ${ }^{30,46}$

Present findings were also consistent with studies done by Desai PD et al., Morimoto et al ., Dejak et al ., Santos et al ., Dalpino et al ., Yamanel et al ., Jensen et al ., and Eackle et al .,32,42,43,44.46,47,48 Desai PD et al. in their study reported that fracture resistance of tooth restored with ceramic inlay is as good as intact tooth or more and fracture resistance of tooth restored with hybrid composite is less than normal tooth and tooth restored with ceramic inlay. Marimoto et al . reported that fracture strength of teeth restored with inlay and onlay ceramics are near to normal teeth. ${ }^{48}$ Dejak et al . also reported that adhesively bonded composite resin and ceramic inlay reinforce the structure of the posterior teeth. ${ }^{32}$ Santos et al . found in his research that cavity preparation significantly weakens the remaining tooth structure, and direct and indirect intracoronal adhesive restorations can partly restore fracture resistance of teeth weakened by wide cavity preparation. ${ }^{42}$ Dalpino et al . have checked fracture resistance of teeth restored with direct and indirect composite resin and indirect ceramic restorations. They found that bonded indirect ceramic restoration requires higher load to fracture than direct and indirect composite resin restorations. A bonded indirect restoration with ceramic is ideal option for restoring teeth weakened by wide cavity preparation. ${ }^{44}$ Yamanel et al . had done an evaluation on the effects of restorative materials and cavity design on stress distribution on the tooth structures and restorative materials, the results of this study showed that in the case of materials with low elastic moduli, more stress was transferred to the tooth structures. Therefore, compared to the nanofilled composites, the all ceramic inlay and onlay materials tested transferred less stress to the tooth structures. ${ }^{43}$ Eackle et al . found in their study that fewer fractures occur in teeth if cavity preparation is conservative. ${ }^{47}$ The findings of present study, between fracture resistance of intact unprepared tooth and tooth restored with Bulk fill hybrid composite resin were in accordance with the studies done by Jensen et $\mathrm{al}^{46}{ }^{46}$ Ausiello et $\mathrm{al},{ }^{49}$ Dalpino et al and de Freitas et $\mathrm{al}^{50}$ reported no significant difference in fracture resistance between intact teeth and teeth restored with composite resin. De Freitas et al 50 investigated the effect of various adhesive restorative techniques on fracture resistance of maxillary premolars. The results showed that fracture resistance of the teeth restored with direct composite resin was not statistically different from that of intact teeth. ${ }^{46}$ Ausiello et al conducted a study on fracture resistance of endodonticallytreated premolars restored with adhesive restoration and concluded that fracture resistance of sound intact tooth 
and tooth restored with direct composite was not significatly different and several adhesive restorative system could satisfactorily be used to restore teeth after endodontic therapy. ${ }^{49}$ Dalpino et al conducted a study on fracture resistance of teeth directly and indirectly restored with composite resin and indirectly restored with ceramic materials and demonstrated that a bonded direct and indirect restoration could satisfactorily be an ideal option for restoring teeth weakened by wide cavity preparation. ${ }^{50}$

Composite material used in this study was bulk fill hybrid composite resin, (X-tra fil, bulkfill, Voco, Germany). Jon Peter Vandewalker et al in their study stated that compared to the incrementally placed composite (Filtek Z250), the new dualcure, bulk-fill restorative composite resins in self-cure mode had unlimited depth of cure along with similar fracture toughness and porosity formation. However, they also exhibited greater polymerization shrinkage and microleakage. ${ }^{51}$ de Assis FS et al found that between Bulk fill material restorations and incrementally filled composite restorations fracture resistance, microtensile bond strength, and marginal integrity values were not statistically significantly affected by application technique or preparation size. ${ }^{52}$ Above studies prove that bulk fill composite material posses similar mechanical properties as incrementally placed Direct posterior composite resins.

From the findings in this In vitro study it can be said that Ceramic inlay is a better posterior restorative alternative as compared to Hybrid composite resin as far as the fracture resistance is concerned and Hybrid composite resin can increase fracture resistance of a tooth to a level comparable with that of intact tooth. However further In vivo studies are to be conducted to evaluate the clinical success and fracture resistance of Ceramic inlays and Hybrid composite resin as Posterior restorative material.

\section{Conclusion}

Material knowledge has evolved, new materials have been developed like the ceramic and hybrid composite resin. Based on the results obtained under in vitro experimental conditions of this study, the following conclusions can be reached.

1. It can be said that Ceramic inlay is a better posterior restorative alternative as compared to Hybrid composite .

2. The hypothesis that direct composite resin and Ceramic inlay restorations would increase fracture resistance to a level comparable with that of intact teeth was accepted.

From this in-vitro study it can be concluded that adhesively bonded restorations such as composite and ceramic inlays are good and optimal replacement for lost tooth structure. Ceramic inlay is better restorative alternative as compared to direct composite resin as far as the fracture resistance is concerned. However further In vivo studies are to be conducted to evaluate the clinical success and fracture resistance of Ceramic inlays and Hybrid composite resin as Posterior restorative material.

References

[1]. Joynt RB, Davis EL. Fracture resistance of posterior teeth restored with glass-ionomer-composite resin system. J Prosthet Dent. 1989, 62:28-31.

[2]. Powers M John. Craig's Restorative Dental Materials. 12th Edition. (New Delhi:Reed Elsevier India Pvt ltd , 2006) . (p.484-486)

[3]. Desai PD, Das UK. Comparison of fracture resistance of teeth restored with ceramic inlay and resin composite: an in vitro study. Indian J Dent Res 2011, 22:877.

[4]. Arvind Shenoy. Is it the end of the road for dental amalgam? A critical review. J Conserv Dent. 2008 Jul-Sep, 11(3): 99-107.

[5]. Knosp. Gold in dentistry: Alloys, uses and performance. Gold Bulletin 2003, 36(3):93-102.

[6]. Henry E. Fayle. Gold inlay failures and some causes. University of Texas, Dental Branch April 1973Volume 29, Issue 4, Pages 439441.

[7]. Choi JY, Lee HH, Kim HW. Bioactive sol-gel glass added ionomer cement for the regeneration of tooth structure. J Mater Sci Mater Med. 2008;19:3287-94. [PubMed: 18483787]

[8]. Yli-Urpo H, Lassila LV, Närhi T, Vallittu PK. Compressive strength and surface characterization of glass ionomer cements modified by particles of bioactive glass. Dent Mater. 2005;21:201-9. [PubMed: 15705426]

[9]. Kampouropoulos D, Paximada C, Loukidis M, Kakaboura A. The influence of matrix type on the proximal contact in Class II resin composite restorations. Oper Dent J. 2010;35(4):454-462.

[10]. Moorthy A, Hogg CH, Dowling AH, Grufferty BF, Benetti AR, \& Fleming GJ (2012) Cuspal deflection and microleakage in premolar teeth restored with bulk-fill flowable resin-based composite base materials. Journal of Dentistry 40(6) 500-505.

[11]. Lutz F. State of the art of tooth-colored restoratives. Oper Dent 1996; 21:237-248.

[12]. Ritter AV, Baratieri LN. Ceramic restorations for posterior teeth: guidelines for the clinician. J Esthet Dent 1999; 11:1172-1185.

[13]. Michelini FS, Belser UC, Scherrer SS, De Rijk WG. Tensile bond strength of gold and porcelain inlays to extracted teeth using three cements. Int J Prosthodont 1995;8:324-31.

[14]. Hikita K, Van Meerbeek B, De Munck J, Ikeda T, Van Landuyt K, Maida T, et al. Bonding effectiveness of adhesive luting agents to enamel and dentin. Dent Mater 2007;23:71-80.

[15]. Yamada Y, Tsubota Y, Fukushima S. Effect of restoration method on fracture resistance of endodontically treated maxillary premolars. Int J Prosthodont 2004;17:94-8.

[16]. Manhart J, Chen HY, Neuerer P, Scheibenbogen-Fuchsbrunner A, Hickel R. Three year clinical evaluation of composite and ceramic inlays. Am J Dent 2001;14,95-9.

[17]. Thordrup M, Isidor F, Horsted-Bindslev P.Comparison of marginal fit and microleakage of ceramic and composite inlays: an in vitro study. J Dent 1994;22:147-53. 
[18]. Mehl A, Kunzelmann KH, Folwaczny M,Hickel R. Stabilization effects of CAD/CAM ceramic restorations in extended MOD cavities. J Adhes Dent 2004;6:239-45.

[19]. Bremer BD, Geurtsen W. Molar fracture resistance after adhesive restoration with ceramic inlays or resin-based composites. Am $J$ Dent 2001; 14,216-20.

[20]. Soares CJ, Martins LR, Fernandes Neto AJ, Giannini M. Marginal adaptation of indirect indirect composites and ceramic inlay systems.Oper Dent 2003;28:689-94.

[21]. Soares CJ, Martins LR, Pfeifer JM, Giannini M. Fracture resistance of teeth restored with indirect-composite and ceramic inlay systems. Quintessence Int 2004;35:281-6.

[22]. St-Georges AJ, Sturdevant JR, Swift EJ Jr, Thompson JY. Fracture resistance of prepared teeth restored with bonded inlay restorations. J Prosthet Dent 2003;89:551-7.

[23]. Brunton PA, Cattell P, Burke FJ, Wilson NH. Fracture resistance of teeth restored with onlays of three contemporary toothcolored resin-bonded restorative materials. J Prosthet Dent 1999;82:167-71.

[24]. da Silva SB, Hilgert LA, Busato AL. Fracture resistance of resin-based composite and ceramic inlays luted to sound human teeth. Am J Dent 2004;17:404-6.

[25]. Cotert HS, Sen BH, Balkan M. In vitro comparison of cuspal fracture resistances of posterior teeth restored with various adhesive restorations. Int J Prosthodont 2001;14:374-8.

[26]. Dalpino PH, Francischone CE, Ishikiriama A, Franco EB. Fracture resistance of teeth directly and indirectly restored with composite resin and indirectly restored with ceramic materials. Am J Dent 2002; 15:389-94.

[27]. Shor A, Nicholls J, Phillips KM, Libman WJ. Fatigue load of teeth restored with bonded direct composite and indirect ceramic inlays in MOD class II cavity preparations. Int J Prosthodont 2003;16:64-9.

[28]. Magne P, Belser UC. Porcelain versus composite inlays/onlays: effects of mechanical loads on stress distribution, adhesion, and crown flexure. Int J Periodontics Restorative Dent 2003;23:543-55.

[29]. Ausiello P, Rengo S, Davidson CL, Watts DC. Stress distributions in adhesively cemented ceramic and resin-composite Class II inlay restorations: a 3D-FEA study. Dent Mater 2004;20:862-72.

[30]. Ragauska A, Apse P, Kasjanovs V, Berzina-Cimdina L. Influence of ceramic inlays and composite fillings on fracture resistance of premolars in vitro. Stomatologija. 2008;10(4):121-6.

[31]. Gorman CM, McDevitt WE, Hill RG. Comparison of two heatpressed all-ceramic dental materials. Dent Mater 2000; 16: 389-95

[32]. Dejak B, Mlotkowski A. Three-dimensional finite element analysis of strength and adhesion of composite resin versus ceramic inlays in molars. J Prosthet Dent 2008;99:131-40.

[33]. Tyas MJ, Anusavice KJ, Frencken JE, Mount GJ. Minimal intervention dentistry--a review. FDI Commission Project 1-97. Int Dent J2000;50:1-12.

[34]. de V Habekost L, Camacho GB, Azevedo EC, Demarco FF. Fracture resistance of thermal cycled and endodontically treated premolars with adhesive restorations. J Prosthet Dent2007;98:186-92.

[35]. Fusayama T. Posterior adhesive composite resin: a historic review. J Prosthet Dent 1990;64:534-8.

[36]. Nasedkin JN. Porcelain posterior resin-bonded restorations: current perspectives on esthetic restorative dentistry; Part II. J Can Dent Assoc 1988; 54(7):499-506.

[37]. Rosenblum MA, Schulman A. A review of all-ceramic restorations. J Am Dent Assoc 1997; 128(3):297-307.21.

[38]. Peutzfeldt A. Indirect resin and ceramic systems. Oper Dent 2001; (Suppl 6): 153-76.

[39]. Boushell LW, Ritter AV. Ceramic inlays: A case presentation and lessons learned from the literature. J Esthet Restor Dent 2009;21:77-87.

[40]. Krifka S, Anthofer T, Fritzsch M, Hiller KA, Schmalz G, Federlin M. Ceramic inlays and partial ceramic crowns; influence of remaining cusp wall thickness on the marginal Integrity and enamel crack formation in vitro. Oper Dent 2009;34:32-42.

[41]. Cobankara FK, Unlu N, Cetin AR, Ozkan HB. The effect of different restoration technique on the fracture resistance of endodontically treated molars. Oper Dent 2008;33:526-33.

[42]. Santos MJ, Bezerra RB. Fracture resistance of maxillary premolars restored with direct and indirect adhesive technique. J Can Dent Assoc 2005;71:585.

[43]. Yamanel K, Caglar A, Gülsahi K, Ozden UA. Effect of different ceramic and composite materials on stress distribution in inlay and onlay cavities; 3D finite element analysis. Dent Mater J 2009;28:661-70.

[44]. Esquivel-upshaw JF, Anusavice KJ, Yang MC, Lee RB. Fracture resistance of all ceramic and metal ceramic inlays. Int J Prosthet 2001;14:109-14.

[45]. Burke FJT, Wilson NHF, Watts DC. The effect of cuspal coverage on the fracture resistance of teeth restored with indirect composite resin restorations. Quintessence Int 1993;24:875-880.

[46]. Jensen ME, Redford DA, Williams BT, Gardner F. Posterior etched-porcelain restorations: an in vitro study. Compend Contin Educ Dent 1987;8:615-622.

[47]. Eackle WS, Maxwell EH, Braly BV. Fractures of posterior teeth in adults. J Am Dent Assoc 1986;112:215-218.

[48]. Morimoto S, Vieira GF, Agra CM, Sesma N, Gil C. Fracture strength of teeth restored with ceramic inlays and overlays. Braz Dent J 2009;20:143-8.

[49]. Ausiello P, De Gee AJ, Rengo S, Davidson CL. Fracture resistance of endodontically-treated premolars adhesively restored. Am J Dent 1997; 10(5):237-41.

[50]. de Freitas CR, Miranda ML, Andrade MF, Flores VH, Vaz LG, Guimaraes C. Resistance to maxillary premolar fractures after restoration on class II preparations with resin composite or ceromer. Quintessence Int, 33(8), 589-94.

[51]. Jon Peter Vandewalker, Jeffery A. Casey, Todd A. Lincoln, Kraig S. Vandewalle. Properties of dual-cure, bulk-fill composite resin restorative materials. General Dentistry, Dental Materials, March/April 2016; 68-7

[52]. de Assis FS, Lima SN, Tonetto MR, Bhandi SH, Pinto SC, Malaquias P, Loguercio AD, Bandéca MC. Evaluation of Bond Strength, Marginal Integrity, and Fracture Strength of Bulk- vs Incrementally-filled Restorations. J Adhes Dent. 2016;18(4):317-23. doi: 0.3290/j.jad.a36516. 